\title{
Aerosol Optical Thickness and PM10 Study by Using a Handheld Spectroradiometer Over Penang
}

\author{
Tan Fuyi, Lim Hwee San, Mohd. Zubir Mat Jafri and K. Abdullah \\ School of Physics, UniversitiSains Malaysia, \\ Malaysia
}

\section{Introduction}

Knowledge of the parameters that are related to the optical properties of atmospheric aerosols is essential for the determination of their climatic effects, development of techniques for remote sensing of aerosol from space or the necessary correction of atmospheric effects in satellite imagery (Sanchez, et al., 1998). The AOT values were derived from the measured transmittance. AOT, $\tau$, is a measure of aerosol loading in the atmosphere (Christopher, et al., 2002). Generally, a higher AOT value indicates higher column of aerosol loading and therefore low visibility (Wang and Christopher, 2003).

Atmospheric components (aerosol and molecules) scatter and absorb solar radiation. This study investigated the use of a handheld spectroradiometer for the retrieval of atmospheric optical thickness (AOT) values over Penang Island. A set of spectroradiometer measured transmittance data was used to derive the aerosol optical thickness (AOT) in the atmosphere. The transmittance values were measured in spectral region from $350 \mathrm{~nm}$ to 1050nm at the earth surface. The locations were determined with a Global Positioning System (GPS) receiver. We selected the values at 550nm for the present analysis. This study introduces an economical and a simple technique for retrieval of AOT for remote sensing application. The transmittance values were measured around the PenangIsland. Particulate matters of size less than 10 micron (PM10) were collected simultaneously with the acquisition of the transmittance measurements. The results of the analysis indicated that the AOT values were linearly correlated with the PM10 readings.

The objective of this study was to explore the relationship between aerosol optical thickness (AOT) derived from the spectroradiometer transmittance measurements and the correlation of particulate matter less than 10 micron (PM10). PM10 values were colleted simultaneously with the transmittance measurements. This study showed that there was a good correlation between the derived AOT and the measured PM10. In this study, we present results from ground-based measurements for PM10 mapping.

Many researchers have conducted satellite monitoring of the AOT [Husar, et al., (1997) and Liu, et al., (2002), Jiang, et al., (2007) and Guo, et al., (2009)]. In this study, we present a method for air quality mapping from ground-based measurements. Typically, ground based measurements were made with a device of sun photometer. In this study, our purpose is to generate AOT and PM10 maps over Penang Island, Malaysia by using a handheld spectroradiometer. The transmittance values were measured using a handheld 
spectraradiometer. The sensitivity of this type of spectroradiometer is between the spectral wavelengths from $350 \mathrm{~nm}$ to $1050 \mathrm{~nm}$. The wells know Beer-Lambert law was used in this study to retrieve AOT values from the transmittance value measurements. AOT and PM10 maps were generated using Kriging interpolation techniquebased on the measured data. This study indicates that the spectroradiometer is a useful tool for retrieval of AOT and PM 10 values in Penang, Malaysia

\section{Study area}

The study area is the Penang Island, Malaysia, located within latitudes $5^{\circ} 9^{\prime} \mathrm{N}$ to $5^{\circ} 33^{\prime} \mathrm{N}$ and longitudes $100^{\circ} 09^{\prime} \mathrm{E}$ to $100^{\circ} 30^{\prime} \mathrm{E}$. The map of the study area is shown in Figure 1. Penang Island is located in equatorial region and enjoys a warm equatorial weather the whole year. Therefore, it is impossible to get the $100 \%$ cloud free satellite image over Penang Island. But, the satellite image chosen is less than $10 \%$ of cloud coverage over the study area. Penang Island located on the northwest coast of Peninsular Malaysia.

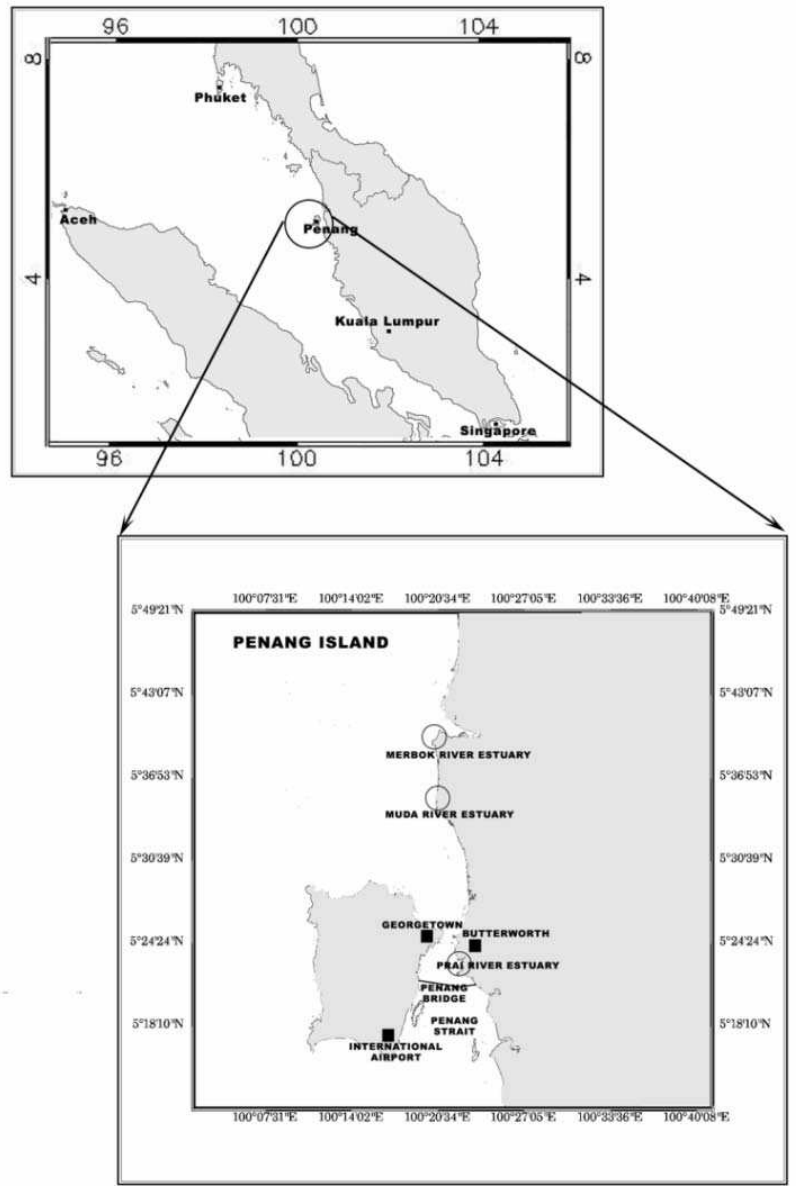

Fig. 1. The study area 
Penang is one of the 13 states of the Malaysia and the second smallest state in Malaysia after Perlis. The state is geographically divided into two different entities - Penang Island (or "Pulau Pinang" in Malay Language) and a portion of mainland called "SeberangPerai" in Malay Language. Penang Island is an island of 293 square kilometres located in the Straits of Malacca and "SeberangPerai" is a narrow hinterland of 753 square kilometres (Tan, et al., 2010). The island and the mainland are linked by the $13.5 \mathrm{~km}$ long Penang Bridge and ferry.

Penang Island is predominantly hilly terrain, the highest point being Western Hill (part of Penang Hill) at 830 metres above sea level. The terrain consists of coastal plains, hills and mountains. The coastal plains are narrow, the most extensive of which is in the northeast which forms a triangular promontory where George Town, the state capital, is situated. The topography of "SeberangPerai" is mostly flat. Butterworth, the main town in "SeberangPerai", lies along the "Perai" River estuary and faces George Town at a distance of $3 \mathrm{~km}$ (2 miles) across the channel to the east (Tan, et al., 2010).

The Penang Island climate is tropical, and it is hot and humid throughout the year. with the average mean daily temperature of about $27^{\circ} \mathrm{C}$ and mean daily maximum and minimum temperature ranging between $31.4^{\circ} \mathrm{C}$ and $23.5^{\circ} \mathrm{C}$ respectively. However, the individual extremes are $35.7^{\circ} \mathrm{C}$ and $23.5^{\circ} \mathrm{C}$ respectively. The mean daily humidity varies between $60.9 \%$ and $96.8 \%$. The average annual rainfall is about $267 \mathrm{~cm}$ and can be as high as $624 \mathrm{~cm}$ (Tan, et al., 2010).

\section{Data acquisition}

The corresponding PM10 measurements were collected at the several selected locations around the Penang Island between 9.00 a.m. to 3.00 p.m. A handheld spectroradiometer was used to collect the sky transmittance data over Penang Island, Malaysia campus on 24th December 2008 from 40 stations in the USM campus (Fig. 2). The AOT was calculated based on the Beer-Lambert-Bouguer law. Table 1 shows the specification of the ASD handheld spectroradiometer used in this study.

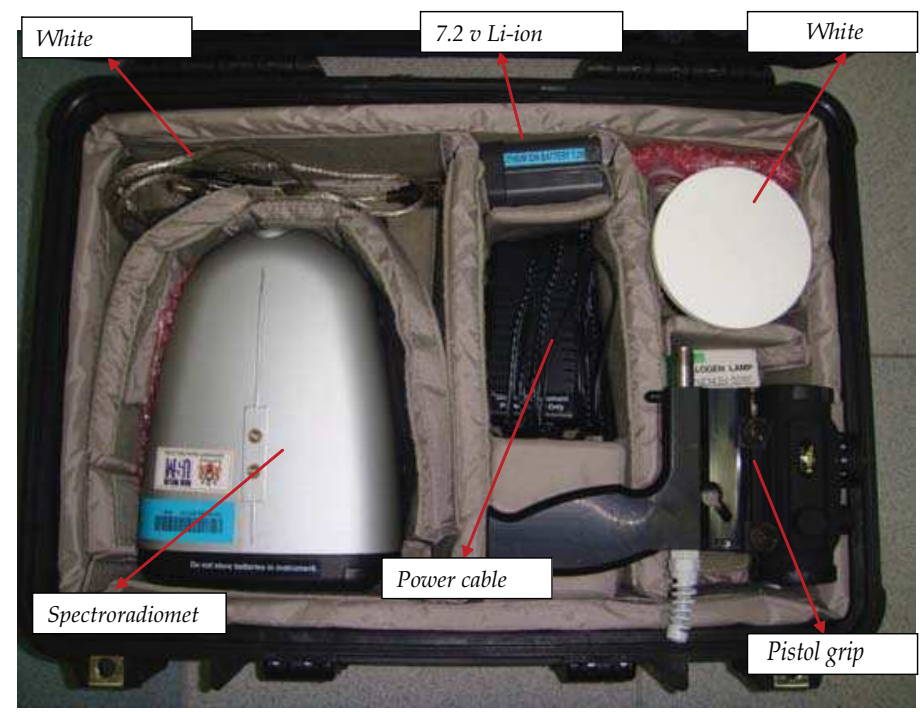

Fig. 2. TheASD handheld Spectroradiometer 


\begin{tabular}{|l|l|}
\hline $\begin{array}{l}\text { FieldSpec }{ }^{\circledR} \text { HandHeld } \\
(325-1075 n m)\end{array}$ & $\begin{array}{l}\text { A field portable, lightweight, battery powered } \\
\text { spectroradiometer. }\end{array}$ \\
\hline Spectral Range: & $325-1075 \mathrm{~nm}$. \\
\hline Sampling Interval : & $1.6 \mathrm{~nm}$. \\
\hline Spectral Resolution: & $3.5 \mathrm{~nm}$ at $700 \mathrm{~nm}$. \\
\hline $\begin{array}{l}\text { Noise Equivalent Delta Radiance } \\
\text { (NeDL): }\end{array}$ & $5.0 \times 10^{\wedge}-9 \mathrm{~W} / \mathrm{cm}^{\wedge} 2 / \mathrm{nm} / \mathrm{sr} @ 700 \mathrm{~nm}$. \\
\hline Weight: & $1.2 \mathrm{~kg}$ including battery pack. \\
\hline Size: & $22 \times 16 \times 8.2 \mathrm{~cm}$. \\
\hline
\end{tabular}

Table 1. Specification of the ASD handheld Spectroradiometer

\section{Methodology}

The transmittance data over PenangIsland on 24th December 2008 was used in this study. The observation site is located in the northern region of the Peninsular Malaysia. The spectroradiometer measure the atmospheric transmittance from $350 \mathrm{~nm}$ to $1050 \mathrm{~nm}$. The data that have been used in this study were collected at 40 locations in Penang, Malaysia.

The AOT is calculated based on the Beer-Lambert-Bouguer law. The AOT is related to the transmission by the expression

$$
T_{d \lambda}=e^{-\frac{\tau_{\lambda}}{u_{s}}} \quad \text { (Vermote, et al., 1997) }
$$

where

$T_{d \lambda}=$ transmittance for direct irradiance at wavelength, $\lambda$

$u_{s}=\operatorname{cosines}(\theta), \theta$ is the zenith angle

AOT values were obtained after performing the sequence of the following calculations:

1. First, we measured the total solar irradiance. This was done by measuring the radiance reflected from a Spectralon panel placed perpendicular to the direction of the Sun. The measured radiance was converted into irradiance by multiplying by $\Pi$ and then divided by the reflectance of the Spectralon panel.

2. Second, we measured the diffuse irradiance. This step was performed with the same Spectralon panel maintained in the same orientation as in step 1. The panel was shaded from direct sunlight using a disk of black painted cardboard mounted on a stick. The size of the disk and distance to the panel should be such that the shadow of the disk on the panel is just sufficient to fully shade the area viewed by the FieldSpec HH. As in step 1, we measured the reflected radiance. Again, the measured radiance is converted to irradiance by multiplying by $\Pi$ and then dividing by the reflectance of the Spectralon panel.

3. Third, we computed the direct solar irradiance by subtracting the diffuse irradiance from the measured total solar irradiance. 
4. Fourth, we computed the top-of-atmosphere (TOA) solar irradiance values corresponding to the wavelengths of the spectra measured by the FieldSpec HH. In this study, Wehrli 1985 AM0 Spectrum was chosen to calculate the TOA spectra and interpolate it to the FieldSpec $\mathrm{HH}$ wavelengths, multiplying by cosines solar angle and then correct for the exact Earth-Sun distance factor, D, given by Spencer, 1971 as

$$
\begin{aligned}
& D=1.00011+0.034221 \cos \phi \\
& +0.00128 \sin \phi+0.000719 \cos 2 \phi \\
& +0.000077 \sin 2 \phi
\end{aligned}
$$

The day angle, $\phi$, in radians is represented by

$$
\phi=2 \pi(d-1) / 365
$$

where $d$ is the day number of a year (1-365)

5. Finally, we computed the atmospheric transmission by dividing the direct solar irradiance computed in step 3 by the top of atmosphere values calculated in the fourth step. This was done by first exporting the FieldSpec $\mathrm{HH}$ spectrum to a text file, importing the text file into a program like MS Excel and then performing the calculations in Excel. Then the AOT values were computed using Equation (1).

\section{Data analysis and results}

The transmittance values were measured using a handheld spectraradiometer. The sensitivity of this type of spectroradiometer is between the spectral wavelengths from 350 $\mathrm{nm}$ to $1050 \mathrm{~nm}$. We selected 6 spectral wavelengths in this study centred at $400.5 \mathrm{~nm}, 500.5$ $\mathrm{nm}, 600.5 \mathrm{~nm}, 700 \mathrm{~nm}, 800 \mathrm{~nm}$ and $900 \mathrm{~nm}$. These selected 6 bands are based on the Wehrli 1985 AM0 Spectrum. Then the transmittance values were used to derive the AOT values using Equation (1). AOT maps were created using Kriging interpolation technique for estimating aerosol values to be associated to their distribution patterns (Figure 3).

In this study, we used PM10 as air quality parameter measurements over Penang Island. The relationship between AOT and PM10 was investigated in this study and we discovered that there was a linear relationship between PM10 and AOT. The linear correlation coefficient (R) was greater than 0.8 (Figure 3). Several studies have indicated linear relationship between these parameter [Christopher and Wang, (2003) and Wang and Christopher, (2003)]. We can clearly see from Figure 4 that PM10 values was increasing as the AOT values increasing. Therefore AOT is a useful information for retrieval of PM 10 values.

From our experimental data set, we can see the PM10 increases as the AOT increases. This mean that as the AOT values increases these is an increase of the concentration of PM10. Therefore, we obtained a positive correlation between AOT and PM10. From the AOT and PM10 maps, we can see that the high concentration of the AOT and PM10 values was located near the Bayan Lepas and Prai industrial areas (Black circle) and Georgetown urban areas (Red circle) (Figures 3 and 5). This was due to the high density of population area and industrial area respectively. The air pollution caused by industry has even more grave effects than vehicle exhaust fumes 


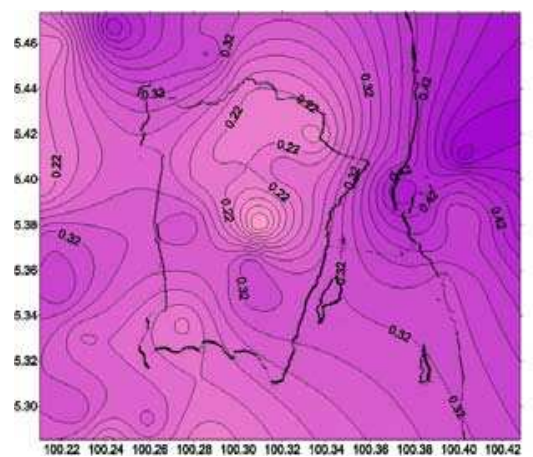

(a)

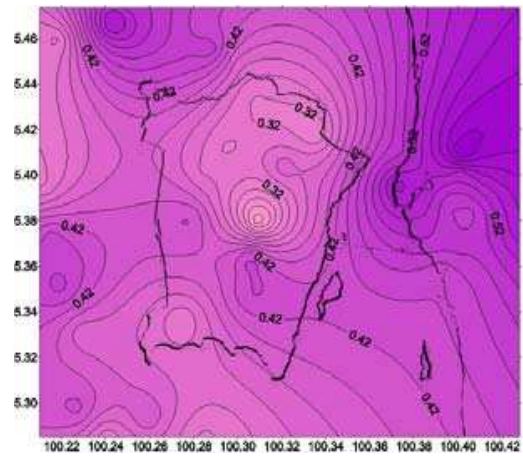

(c)

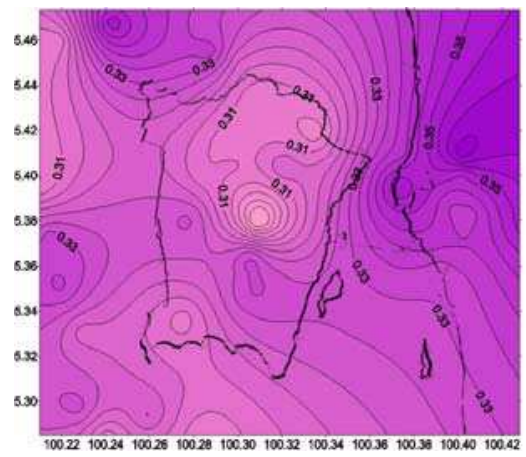

(e)

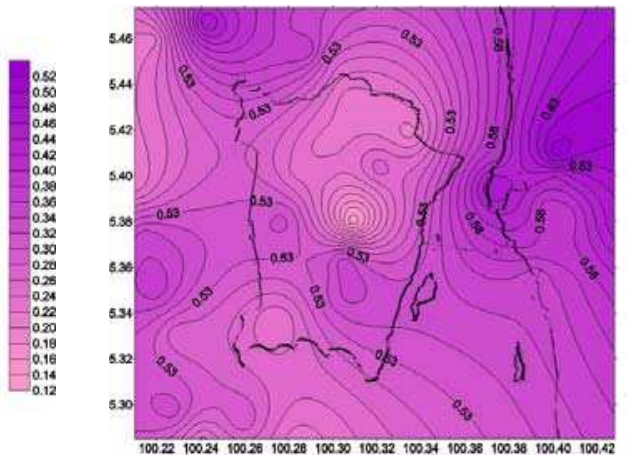

(b)

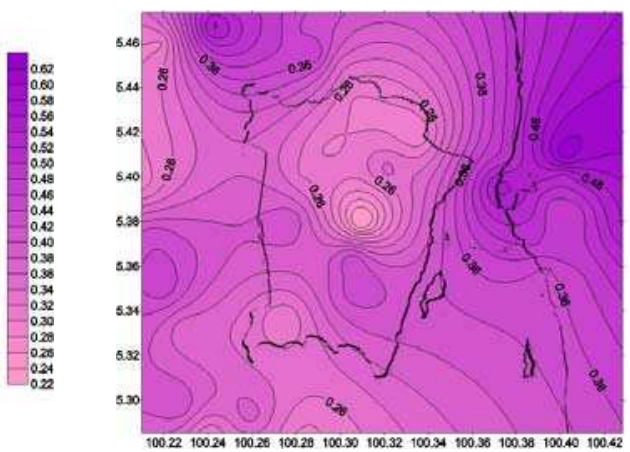

(d)

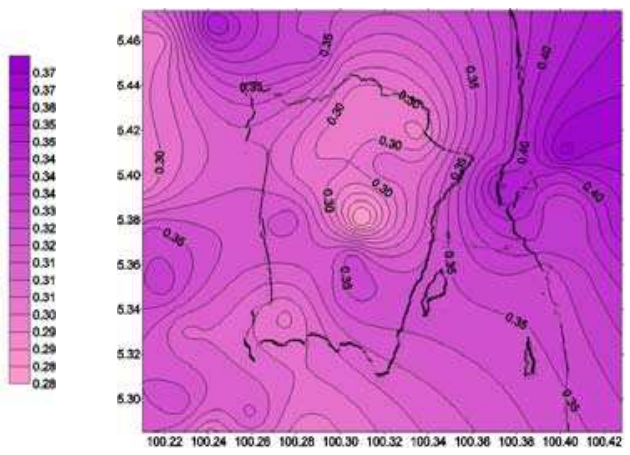

(f)

Fig. 3. AOT map for (a) $400.5 \mathrm{~nm}$, (b) $500.5 \mathrm{~nm}$, (c) $600.5 \mathrm{~nm}$, (d) $700 \mathrm{~nm}$, (e) $800 \mathrm{~nm}$ and (f) $900 \mathrm{~nm}$ 


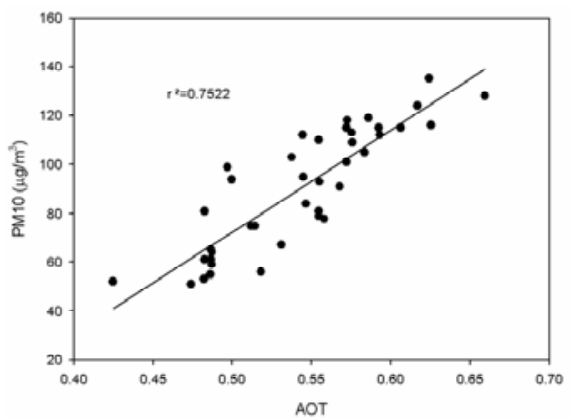

(a)

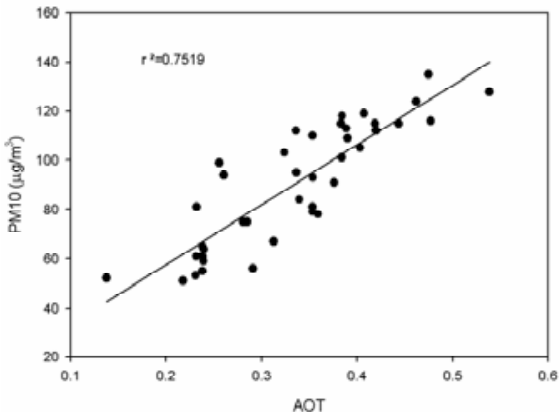

(c)

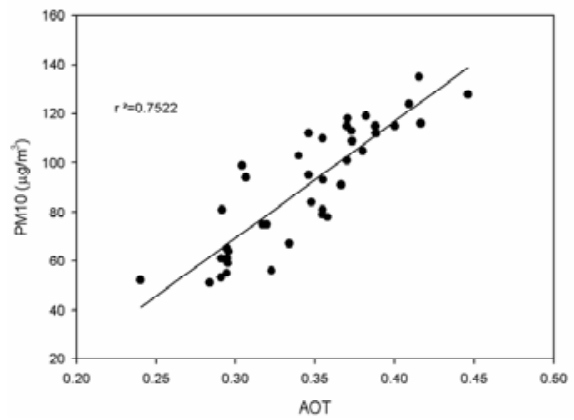

(e)

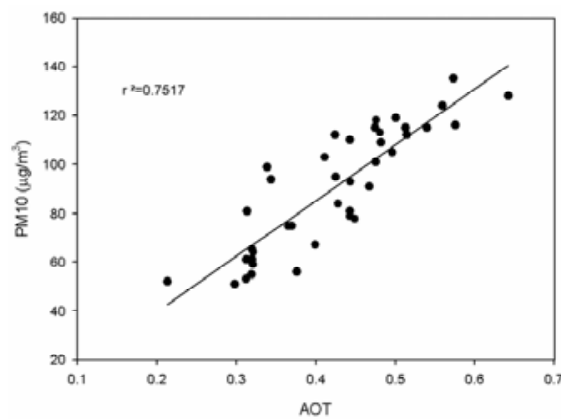

(b)

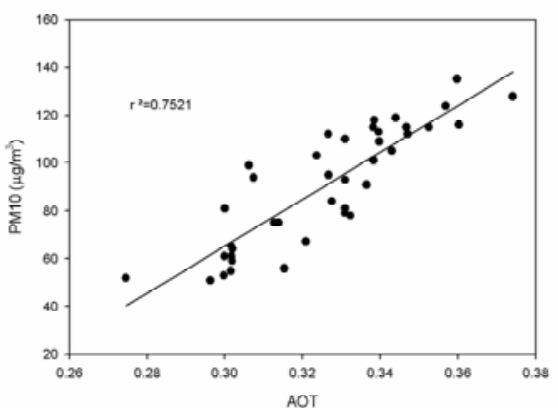

(d)

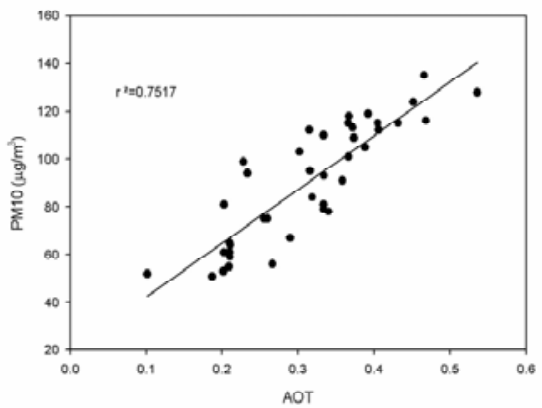

(f)

Fig. 4. A linear correlation between AOT and PM10 $(\mu \mathrm{g} / \mathrm{m} 3)$ values for (a) $400.5 \mathrm{~nm}$, (b) $500.5 \mathrm{~nm}$, (c) $600.5 \mathrm{~nm}$, (d) $700 \mathrm{~nm}$, (e) $800 \mathrm{~nm}$ and (f) $900 \mathrm{~nm}$

\section{Conclusion}

AOT retrieval was produced by the handheld spectroradiometer from the atmospheric transmittance measurements. The results showed that there was a good agreement between AOT and PM10. The spectroradiometer retrieved AOT data had a good positive correlation with the PM10 concentration. This indicates that air quality can be retrieved from the spectroradiometer transmittance measurements. The interpolated AOT map can be used to discern air quality categories such as good, moderate and unhealthy to a relatively high 
degree of confidence. A linear relationship between PM10 and AOT was found by this study. Findings can be used to analyze the air pollution levels over Penang Island.

\section{Acknowledgements}

This project was carried out using the USM short term grants and Science Fund. The authors gratefully acknowledge the financial support from the RU grant, Relationship Between Heavy Rain, Flash Floods And Strong Winds In Malaysia, Southeast Asia During Tropical Cyclones, account number: 1001/PFIZIK/811152. We would like to thank the technical staff who participated in this project. Thanks are extended to USM for support and encouragement. Special thanks are extended to Jet Propulsion Laboratory, California Institute of Technology, USA for providing free online ASTER DEM data used in this study through GDEM WIST url that follows. https:// wist.echo.nasa.gov/wist-bin/api/ims.cgi?mode=MAINSRCH\&JS=1. Thanks are extended to USM for support and encouragement.

\section{References}

Christopher, S. A., Zhang, J., Holben, B. N. and Yang, S. K., 2002, GOES-8 and NOAA-14 AVHRR retrieval of smoke aerosol optical thickness during SCAR-B, int. j. remote sensing, 23 (22), 4931-4944

Guo, J. P., Zhang, X. Y., Che, H. Z., Gong, S. L., An, X., Cao, C. X., Guang, J., Zhang, H., Wang, Y. Q., Zhang, X. C., Xue, M. and Li, X. L., 2009, Correlation between PM concentrations and aerosol optical depth in eastern China, Atmospheric Environment, 43(37), p.p. 5876-5886

Husar R. B., M. Prospero and L. Stowe, 1997, Characterization of tropospheric aerosols over the oceans with the NOAA advanced very high resolution radiometer optical thickness operational product, Journal Geophysics. Research, 102, 16889-16909

Jiang, X., Liu, Y., Yu, B. and Jiang, M., 2010, Comparison of MISR aerosol optical thickness with AERONET measurements in Beijing metropolitan area, Remote Sensing of Environment, 107(1-2), 15, p.p. Pages 45-53

Liu, G. R., Chen, A. J., Lin, T. H. and Kuo, T. H., 2002, Applying SPOT data to estimate the aerosol optical depth and air quality, Environmental modeling\& software, 17, 3-9

Sanchez Oliveros, C., Olmo Reyes, F. J. danAlados-Arboledas, L., 1998, Determination of aerosol optical thickness from measurements of spectral sky radiance. Journal of aerosol Science, 10, p.p. 1199-1211

Tan, K. C., Lim, H. S., MatJafri, M. Z. and Abdullah, K., 2010, Landsat data to evaluate urban expansion and determine land use/land cover changes in Penang Island, Malaysia, Springer, Environmental Earth Sciences, 60(7), p. p.1509-1521, ISSN: 1866-6280 (Print) 1866-6299 (Online), Available online: http://www.springerlink.com/content/d00w220673408052/. Digital Object Identifier: $10.1007 /$ s12665-009-0286-z

Vermote, E., Tanre, D., Deuze, J. L., Herman, M. and Morcrette, J. J., 1997, Second Simulation of the satellite signal in the solar spectrum (6S), [Online] available: http://www.geog.tamu.edu/klein/geog661/handouts/6s/6smanv2.0_P1.pdf

Wang, J. and Christopher, S. A., 2003, Intercomparison between satellite-derived aerosol optical thickness and PM2.5 mass: Implications for air quality studies, Geophysics Research Letters, 30 (21)

Wehrli 1985 AM0 Spectrum, [Online] available: http://rredc.nrel.gov/solar/spectra/am0/wehrli1985.new.html 


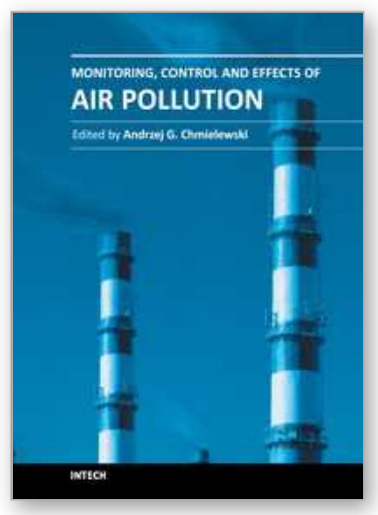

\author{
Monitoring, Control and Effects of Air Pollution \\ Edited by Prof. Andrzej G. Chmielewski
}

ISBN 978-953-307-526-6

Hard cover, 254 pages

Publisher InTech

Published online 23, August, 2011

Published in print edition August, 2011

The book addresses the subjects related to the selected aspects of pollutants emission, monitoring and their effects. The most of recent publications concentrated on the review of the pollutants emissions from industry, especially power sector. In this one emissions from opencast mining and transport are addressed as well. Beside of SOx and NOx emissions, small particles and other pollutants (e.g. VOC, ammonia) have adverse effect on environment and human being. The natural emissions (e.g. from volcanoes) has contribution to the pollutants concentration and atmospheric chemistry governs speciation of pollutants, as in the case of secondary acidification. The methods of ambient air pollution monitoring based on modern instrumentation allow the verification of dispersion models and balancing of mass emissions. The comfort of everyday humanâ $€^{\mathrm{TM}} \mathrm{S}$ activity is influenced by indoor and public transport vehicles interior air contamination, which is effected even by the professional appliances operation. The outdoor pollution leads to cultural heritage objects deterioration, the mechanism are studied and the methods of rehabilitation developed. However to prevent emissions the new technologies are being developed, the new class of these technologies are plasma processes, which are briefly reviewed at the final part of the book.

\title{
How to reference
}

In order to correctly reference this scholarly work, feel free to copy and paste the following:

Tan Fuyi, Lim Hwee San, Mohd. Zubir Mat Jafri and K. Abdullah (2011). Aerosol Optical Thickness and PM10 Study by Using a Handheld Spectroradiometer Over Penang, Monitoring, Control and Effects of Air Pollution, Prof. Andrzej G. Chmielewski (Ed.), ISBN: 978-953-307-526-6, InTech, Available from:

http://www.intechopen.com/books/monitoring-control-and-effects-of-air-pollution/aerosol-optical-thickness-andpm10-study-by-using-a-handheld-spectroradiometer-over-penang

\section{INTECH}

open science | open minds

\author{
InTech Europe \\ University Campus STeP Ri \\ Slavka Krautzeka 83/A \\ 51000 Rijeka, Croatia \\ Phone: +385 (51) 770447 \\ Fax: +385 (51) 686166 \\ www.intechopen.com
}

\author{
InTech China \\ Unit 405, Office Block, Hotel Equatorial Shanghai \\ No.65, Yan An Road (West), Shanghai, 200040, China \\ 中国上海市延安西路65号上海国际贵都大饭店办公楼 405 单元 \\ Phone: +86-21-62489820 \\ Fax: +86-21-62489821
}


(C) 2011 The Author(s). Licensee IntechOpen. This chapter is distributed under the terms of the Creative Commons Attribution-NonCommercialShareAlike-3.0 License, which permits use, distribution and reproduction for non-commercial purposes, provided the original is properly cited and derivative works building on this content are distributed under the same license. 